\title{
PERFORMANCE OF SUSTAINABLE GREEN CONCRETE INCORPORATED WITH FLY ASH, RICE HUSK ASH, AND STONE DUST
}

\author{
Ayesha Siddika ${ }^{a, b, *}$, Md. Ruhul $\operatorname{Amin}^{b}$, Md. Abu Rayhan $^{b}$, \\ Md. Saidul Islam ${ }^{b}$, Md. Abdullah Al Mamun ${ }^{c}$, Rayed Alyousef $^{d}$, \\ Y. H. Mugahed Amran ${ }^{d}$ \\ ${ }^{a}$ University of New South Wales, Sydney, School of Civil and Environmental Engineering, NSW 2052, Australia \\ ${ }^{b}$ Pabna University of Science and Technology, Department of Civil Engineering, Pabna-6600, Bangladesh \\ ${ }^{c}$ Rajshahi University of Engineering $\&$ Technology, Department of Civil Engineering, Rajshahi-6204, Bangladesh \\ ${ }^{d}$ Prince Sattam Bin Abdulaziz University, College of Engineering, Department of Civil Engineering, 11942 \\ Alkharj, Saudi Arabia \\ * corresponding author: a.siddika@unsw.edu.au
}

\begin{abstract}
The performance of a sustainable green concrete with fly ash (FA), rice husk ash (RHA), and stone dust (SD) as a partial replacement of cement and sand was experimentally explored. FA and RHA have a high silica content, are highly pozzolanic in nature and have a high surface area without any treatment. These by-products show filler effects, which enhance concrete's density. Results showed that the FA and RHA materials have good hydration behaviour and effectively develop strength at an early age of concrete. SD acts as a stress transferring medium within concrete, thereby allowing the concrete to be stronger in compression, and bending. Consequently, water absorption capacity of the sustainable concrete was lower than that of the ordinary one. However, a little reduction in strength was observed after the replacement of the binder and aggregate using the FA, RHA and SD, but the reduction was insignificant. The reinforced structure with sustainable concrete containing the FA, RHA, and SD generally fails in concrete crushing tests initiated by flexural cracking followed by shear cracks. The sustainable concrete could be categorized as a perfect material with no significant conciliation in strength properties and can be applied to design under-reinforced elements for a low-to-moderate service load.
\end{abstract}

KEYWORDS: Fly ash, rice husk ash, stone dust, sustainable green concrete, mechanical properties.

\section{INTRODUCTION}

Sustainable construction is gradually becoming challenging due to environmental and economic considerations. Because the main consumer of natural resources is the construction sector that produces a large mass of waste [1]. Concrete is an extensively used construction material that requires a large mass of ingredients and is, thus, costly. Around 5\% - 8\% of global carbon dioxide emissions are generated by the production of cement, which is an important component of a concrete mix 22 4. Meanwhile, natural sands are used in concrete construction, and this utilization adversely affects the natural resources and river bed level [5, 6]. Therefore, the optimization of the uses of cement and natural sands in concrete is a priority. Many available by-products and waste materials can be used in concrete, such as the FA, RHA, palm oil fuel ash, limestone waste, SD, slag, silica fume, fibres, glass and rubber waste [3, 7 15]. The use of these by-products in concrete for waste management not only reduces the material cost but also the waste management cost [2, 11, 16].

The FA is a by-product with high pozzolanic properties produced in large quantities each year from the coal combustion in different industries. An optimum amount of cement can be replaced in concrete by the FA [17. Because of the siliceous type, it reacts aggressively with calcium hydroxide and forms cementitious compound, thereby the strength of the concrete with an addition of the FA gets improved. The addition of the FA lowers the water demand in concrete mix, and thus results in less bleeding and little heat progression [3, 18, 19. The FA has a high silica content and is highly amorphous in nature. The specific surface area of the FA is approximately $300-495 \mathrm{~m}^{2} / \mathrm{kg}$, which helps to produce a high-density concrete matrix [20, 21], and thus the use of finer FA particles results in a higher compressive strength concrete than the use of coarser ones 21. Additionally, the FA enhances the density of concrete in the interfacial transition zone (ITZ) by reducing the permeable voids, which leads to a highly durable and high strength concrete 2224]. Besides, the reduced micro-voids along the ITZ results in the high fracture toughness of the siliceous FA-based concrete 23. Additionally, the FA-based concrete possesses better chloride penetration resistance than OPC concrete and an increased electrical resistivity [25]. The most concerning matter 
of the FA-based concrete is the low strength development rate at an early age due to a low reactivity [25]; but it can gain strength over a long period. Moreover, an ordinary concrete slows down the strength gaining at around 56 days of curing, sometimes stopping altogether, but the FA concrete shows a gradual improvement in strength over a long period of time [3, 26]. The improvement in strength depends on the class and fineness of the FA and other ingredients and admixtures. It is not possible to determine the optimum level of the FA addition for a global application, as the performance varies depending on the source, chemical composition and structure of the FA, and other ingredients in the concrete [27]. However, in literature, the optimum value of replacement of cement by the FA is said to be around $10-25 \%$ wt [3, 21, 22, 27].

Meanwhile, rice husk is a by-product produced in millions of tons per year from agricultural and industrial factories. After burning these rice husks in any industries as fuel, around $20 \%-25 \%$ of RHA is generated. For every tonne of harvested rice, approximately $220 \mathrm{~kg}$ of husks are produced; when these husks are burned, $55 \mathrm{~kg}$ of ash are generated [28. The RHA contains a highly amorphous silica, which is a good supplementary material for cement in concrete [25, 29]. In concrete, the RHA forms a calcium silicate hydrate (C-S-H) gel around cement particles, which leads to a highly dense concrete matrix and resulting in an accelerated early strength development 30 with an average density of around $2200-2550 \mathrm{~kg} / \mathrm{m}^{3}$ [7]. However, the incineration time, temperature, and environment of the combustion of the rice husks affect the specific surface area, amorphous silica, and carbon content of the RHA, and consequently the strength of concrete when used [28]. The pozzolanic activity of the RHA depends on the specific surface area and fineness of its particles. It can be controlled by adopting a controlled combustion and grinding process [31]. Open field burning or a special incineration with a controlled temperature can be applied to produce the RHA from rice husks. However, the RHA, which is produced from an open field uncontrolled burning system, contains high carbon content, which adversely affects the properties of concrete and produces highly crystalline forms in the structure [32, 33. Generally, the RHA contains around $85 \%-95 \%$ amorphous silica and exhibits an eco-friendly behaviour as a supplementary cementing material in concrete 34,36 and can be used at around $10-25 \%$ wt to replace cement in concrete without decreasing the strength [2]. Moreover, the RHA exhibits a good performance even without any further processing and helps to accelerate the early age strength development in concrete [7, 37. The shrinkage and absorption capacities of an ordinary and RHA-based concrete are nearly the same. In optimum levels, additions of FA and RHA in concrete as replacements of cement can reduce carbon dioxide emissions from cement production; this replacement improves the greenness of environment and decreases the overall costs of construction 35. Additionally, when the FA and RHA are used simultaneously in concrete, more beneficial outcomes are being noticed. Because the problems of low reactivity of the FA in concrete and slow strength development in an early age can be overcome by replacing a part of it by the RHA [25, 37]. Moreover, the addition of these supplementary cementitious materials also reveals economic and environmental benefits by reducing the uses of natural limestone, energy consumption and carbon emission from cement production [23, 38. In addition, the mineral additives make sure a high degree of homogenization of the composites in the concrete mix, which leads to smaller internal micro-cracks [39, thus these mineral wastes are suitable for reinforced concrete designed for dynamic loading.

The SD is being produced from stone quarries in a large amount during the processing of stone aggregates. These waste products can be an excellent alternative to natural sands [5] or cement 8] in concrete and can help to develop a sustainable green concrete [40. The highly fine silica content in the SD increases the amorphous content and filler activity, which increase the density of a concrete mix up to a certain limit of replacement. The replacement of fine aggregates by $25 \%$ wt of the SD improves mechanical properties and durability; a further increase in the replaced amount may decrease strength 41. Previous studies have shown that replacing sand with quarry rock dust produces a concrete with an approximate $8 \%-20 \%$ increase in strength [41]. As the amount of the SD addition increases, the density of concrete increases and the absorption of water decreases, which leads to a high durability [42, 43. SD-based concrete has better mechanical properties than ordinary concrete and is cost effective due to the use of waste products 44. A gradation of the SD is required prior to its use as a replacement of sand in concrete. In their study, Bahoria et al. [5] found that the SD with a particle size below $75 \mu \mathrm{m}$ acts as filler, increasing the workability of mix, and decreasing the porosity of the hardened concrete. By contrast, SD with a particle size between $75 \mu \mathrm{m}$ and $6 \mathrm{~mm}$ acts as a fine aggregate. Additionally, very fine SD increases the workability, and a lower amount of superplasticizers are needed in the SD concrete than in an ordinary fine aggregate concrete [43. In his study, Singh et al. [40] reached a contrary conclusion, he found that the water absorption capacity of the SD is higher than that of natural aggregates, thereby its addition reduces the workability of concrete.

However, the performance, when these supplementary materials are being used simultaneously in concrete is still unclear. Thus, this study aims to determine the performance of a sustainable green concrete with a partial replacement of cement by incorporating the FA, RHA, and replacing fine aggregate with the SD in different percentages. Physical and mechanical properties such as water absorption capacity 


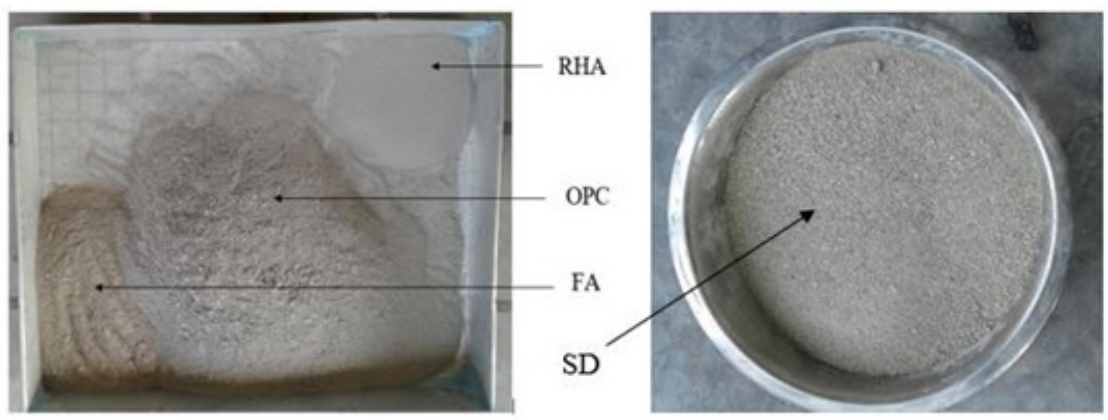

FiguRE 1. Raw materials for concrete specimens.

and load-carrying capacity of the tested specimens were investigated. Compressive, flexural, and splitting tensile strength tests were performed to assess the performance of the sustainable green concrete for eco-friendly construction material systems and their application.

\section{Methodology of EXPERIMENTAL WORK}

\subsection{MATERIAL SELECTION AND SPECIMEN PREPARATION}

The control specimens were prepared with ordinary Portland cement (OPC 43 grade), coarse sand, and crushed stone maintaining a ratio of $1: 2: 4$ with the water-cement ratio of 0.5 . The specific gravity of sand was 2.60, and fineness modulus was $2.50 .20 \mathrm{~mm}$ downgraded stone aggregate was used with the specific gravity of 2.64. The water absorption capacity of sand and stone chips was $2.35 \%$ and $1.50 \%$, respectively.

The FA by-products from cement industries, RHA from different mills and factories, and SD from stone quarries were used in concrete. In sustainable specimens, the RHA and FA were used as replacements of cement. The FA and RHA met the requirements of ASTM C 618 [45. Chemical and physical properties of materials were collected from the manufacturer and supplier. Class-F FA with more than $75 \%$ oxide components $\left(\mathrm{SiO}_{2}+\mathrm{Al}_{2} \mathrm{O}_{3}+\mathrm{Fe}_{2} \mathrm{O}_{3}\right)$ and around $2 \%$ loss of ignition was used in this experiment. As per manufacturer, the FA contained $2.15 \% \mathrm{CaO}$, which is much lower compared to the amount of $61.4 \%$ contained by the OPC used. The RHA was ground and sieved with a 150 mesh sieve. The specific gravity of the RHA was 2.01 , and bulk density was $106 \mathrm{~kg} / \mathrm{m}^{3}$. The specific surface area of the RHA was measured by applying the BET theory 46. The specific surface area of the RHA was $19.7 \mathrm{~m}^{2} / \mathrm{kg}$ after 5 minutes of grinding and contained $79.7 \%$ of $\mathrm{SiO}_{2}$. The average size of the RHA particles was in the range of $90-100$ microns. In addition, the $100 \%$ particles of the OPC and FA passed through the 90 microns opening sieve.

Meanwhile, the specific gravity and fineness modulus of the SD were 2.63 and 2.80, respectively, which meets the fine aggregate gradation criteria as per
ASTM C33 [47. The SD passed through $4.75 \mathrm{~mm}$ opening sieve and around the $24 \%$ that retained on the $1 \mathrm{~mm}$ opening sieve were used for the specimen preparation. Fig. 1 shows the samples.

The specimens were prepared with varying contents of the FA and RHA as replacements of cement and the $\mathrm{SD}$ as a replacement of sand in concrete. Table 1 lists the composition of each type of concrete mix with a specimen ID. Cement and sand in concrete were replaced by different weight percentages of the FA, $\mathrm{RHA}$, and SD. The concrete mix ratios are listed in table 2

\subsection{EXPERIMENTAL TESTS}

A slump test was conducted to evaluate the workability in line with the ASTM C 14348 for all concrete mixes. A water absorption test was carried out for each type of specimen following the ASTM C 642-13 [49]. The percentage of weight gain by dried specimens (dried in oven for $24 \mathrm{~h}$ at around $110^{\circ} \mathrm{C}$ ) after a submersion in water for $24 \mathrm{~h}$ was calculated as water absorption capacity. A compressive strength test was performed with cylindrical specimens with a diameter of $100 \mathrm{~mm}$ and a height of $200 \mathrm{~mm}$ at 28 days of curing using a universal testing machine as per the ASTM C 39 [50]. Meanwhile, a flexural strength test (Fig. 2) with prism beam specimens of $150 \mathrm{~mm} \times 150 \mathrm{~mm} \times 700 \mathrm{~mm}$ was performed for all types of concrete in accordance with the ASTM C78 [51]. A splitting tensile strength test was conducted using cylindrical specimens with a diameter of $100 \mathrm{~mm}$ and a height of $200 \mathrm{~mm}$ for all types of concrete following the ASTM C 496 [52. Fig. 2at 2f illustrates the specimen preparation and the test setups. Each of the tests was done on at least three specimens and the average results were taken.

\section{Results AND Discussion}

\subsection{WORKABILITY}

Fig. 3 shows the slump test results of different concrete mixes. The maximum slump value was found for the control specimen, whereas the minimum slump value is found for the mix with $5 \%$ wt of the FA, $5 \%$ wt of the RHA, and $10 \%$ wt of the SD. The FA and RHA 


\begin{tabular}{lc}
\hline Replacement level & Specimen ID \\
\hline $0 \%$ FA $+0 \%$ RHA $+0 \%$ SD & F0R0S0 \\
$5 \%$ FA $+10 \%$ RHA $+0 \%$ SD & F5R10S0 \\
$10 \%$ FA $+5 \%$ RHA $+0 \%$ SD & F10R5S0 \\
$10 \%$ FA $+10 \%$ RHA $+5 \%$ SD & F10R10S5 \\
$5 \%$ FA $+5 \%$ RHA $+10 \%$ SD & F5R5S10 \\
\hline
\end{tabular}

TABLE 1. Specimen ID and replacement level.

\begin{tabular}{lccccccc}
\hline \multirow{2}{*}{ Specimen ID } & \multicolumn{7}{c}{ Constituents $\left(\mathrm{kg} / \mathrm{m}^{3}\right)$} \\
\cline { 2 - 8 } & Cement & Water & FA & RHA & Fine aggregate & SD & Coarse aggregate \\
\hline F0R0S0 & 380 & 190 & 0 & 0 & 760 & 0 & 1520 \\
F5R10S0 & 323 & 190 & 19 & 38 & 760 & 0 & 1520 \\
F10R5S0 & 323 & 190 & 38 & 19 & 760 & 0 & 1520 \\
F10R10S5 & 304 & 190 & 38 & 38 & 722 & 38 & 1520 \\
F5R5S10 & 342 & 190 & 19 & 19 & 684 & 76 & 1520 \\
\hline
\end{tabular}

TABLE 2. Concrete mix proportion.
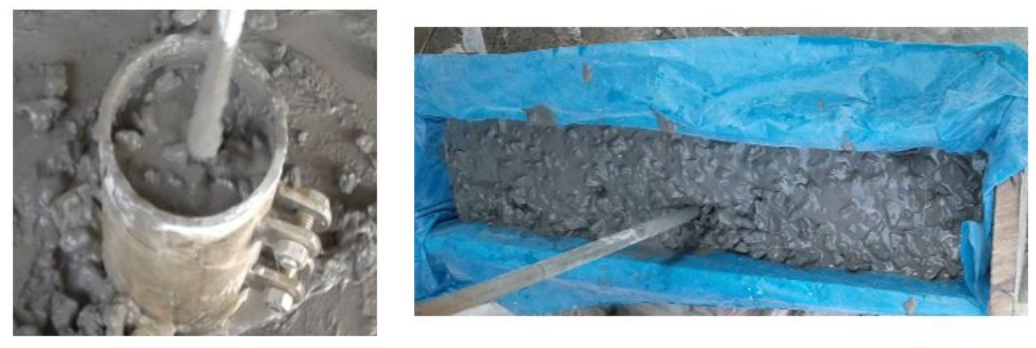

(A) . Casting of specimens.
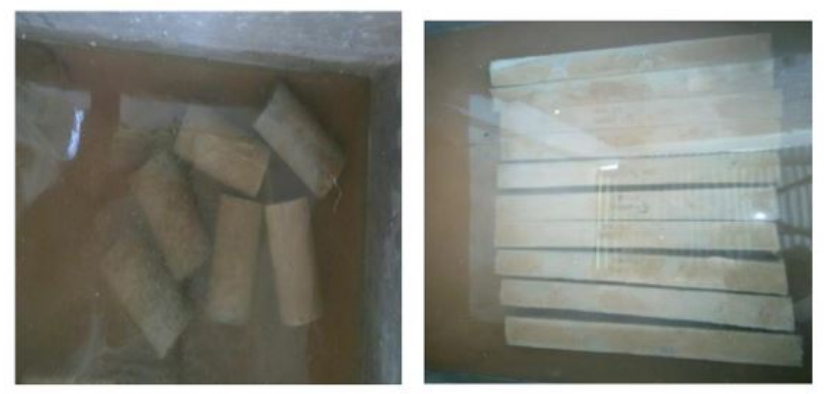

(C) . Curing of specimens.

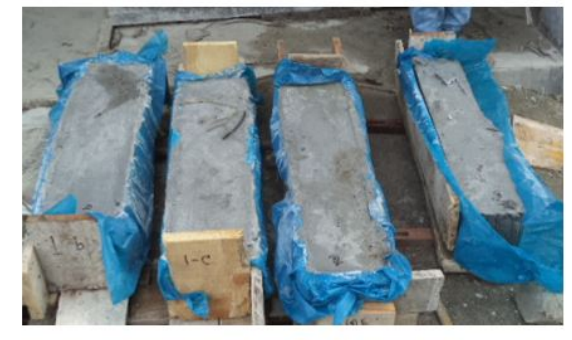

(в) . Hardening of specimens.

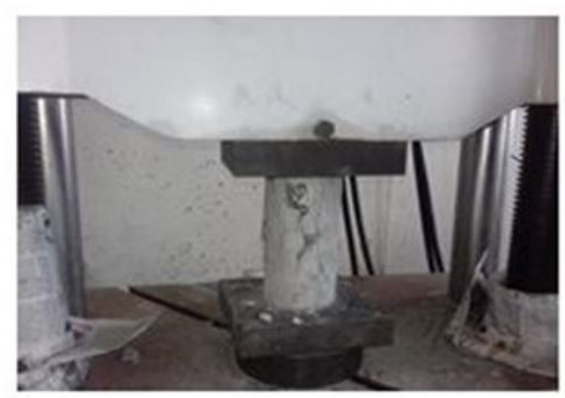

(D) . Compressive strength test.

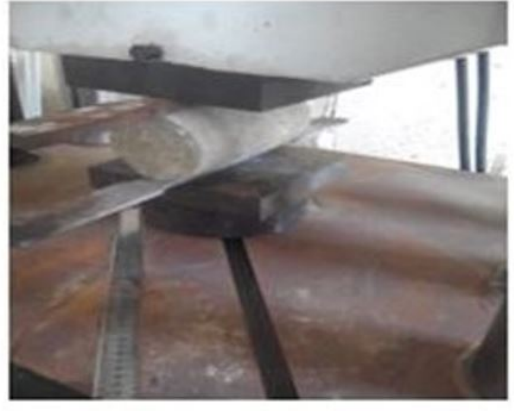

(E) . Splitting tensile strength test.

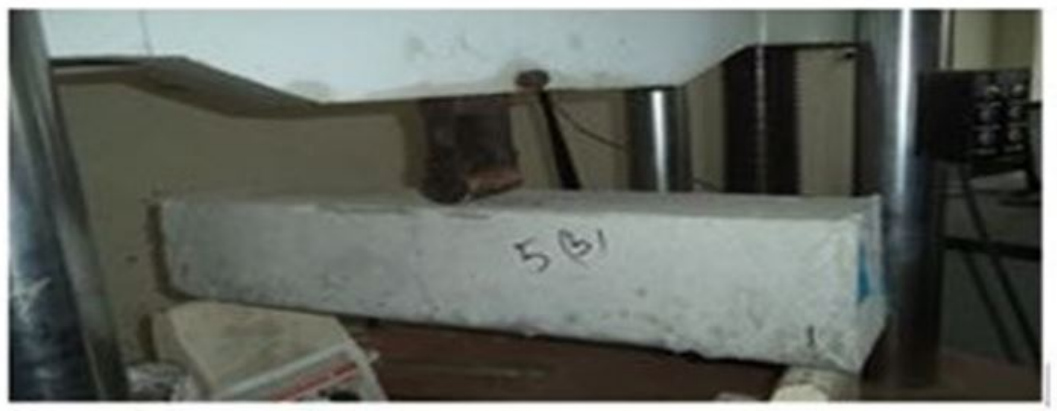

(F) . Flexural strength test.

FIGURE 2. Specimen preparation and test setup. 


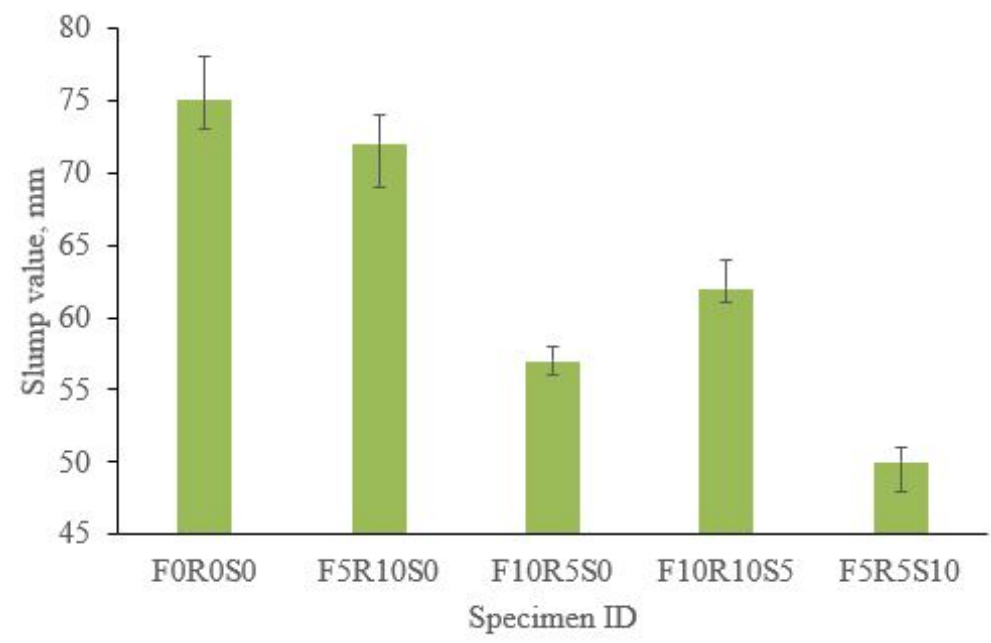

Figure 3. Slump value of different concrete mix.

have a high specific surface area, which leads to an immediate absorption of water after mixing. Hence, the addition of the FA and RHA caused a reduction of the slump value of the concrete mix; but, unexpectedly, a little higher slump was observed for the mix F10R10S5, which can be caused by the reaction between the FA and RHA and variation in mixing process. In general, the addition of the FA causes an increased workability of the concrete mix due the spherical shape of the particles, which was mentioned in several researches [20, 53, 54] and the RHA causes a reduction of the slump value [55]. As observed from the results of this experiment, the FA reduced the slump value of concrete, because it required more water to complete hydration and pozzolanic reactions within the mix as compared to the RHA. This is due to the FA having finer particles than the RHA. Another reason of the high water demand by the concrete mix can be the high carbon content in the RHA and FA [35]. Because of the uncontrolled burning during the production, the FA and RHA used in this experiment had a high carbon content, and thus caused a high water demand and low slump of the concrete mix. Meanwhile, the SD addition also resulted in a reduction of the slump value of the concrete mix, because it has a higher water absorption capacity than natural sands [40]. The addition of the SD in the concrete mix increases interparticle friction, which increases the cohesiveness and stiffness of concrete mixes; thereby resulting in a low slump value, and consequently in a poor workability of that concrete mix [56. For these reasons, the addition of the SD considerably decreased the workability of the concrete mix. To increase the workability of the FA-, RHA-, and SD-based concrete mixes, researchers have suggested specific doses of superplasticizers [43, 44, 55].

\subsection{WATER ABSORPTION CAPACITY}

The addition of very fine pozzolanic particles in a concrete matrix instigates a densely packed and less porous structure, which results in a low water absorption capacity. As shown in Fig. 4 the water absorption capacity of concrete decreased after cement and sand were replaced by the supplementary materials. The FA, RHA, and SD act as filler materials due to their high fineness properties, which produce dense concrete matrix, and thus lowered the water absorption capacity. The specimen of the concrete mix with $5 \%$ wt of the FA and $10 \%$ wt of the RHA has increased water absorption, and this result may be attributed to its less dense matrix caused by imperfect mixing and hydration. Hydration of cementitious materials is important to enhance the binding action and should be closely packed with a high bonding energy to produce less porous structures. The addition of the SD results in an excellent performance of the F5R5S10 specimen with a reduced water absorption capacity of $15.85 \%$. These results are in a good agreement with the study of Ghorbani et al. [42, 57]. During hydration, the calcium hydroxide available for the formation of $\mathrm{C}-\mathrm{S}-\mathrm{H}$ product depends on the content of $\mathrm{CaO}$ in the FA and RHA, and their chemical reactivity is controlled by the active silica content and fineness of both materials [55, 58]. Though, in this experiment, the FA and RHA contained a low amount of $\mathrm{CaO}$ and the relatively coarser RHA caused a lower binding energy during the hydration process and the formation of C-S-H gel was lower compared to cement. Therefore, the porosity of these concrete mixes was increased. The porosity of the F10R10S5 specimen was higher than that of F5R5S10. Because the lower level of cement replacement and a higher stone dust addition, the stronger binding energy and more voids filling phenomenon occurs in the latter specimen [55, 57]. Hence, the water absorption was minimal for the specimen F5R5S10. Therefore, the durability of concrete can be enhanced by adding the FA, RHA, and SD up to an optimum limit. 


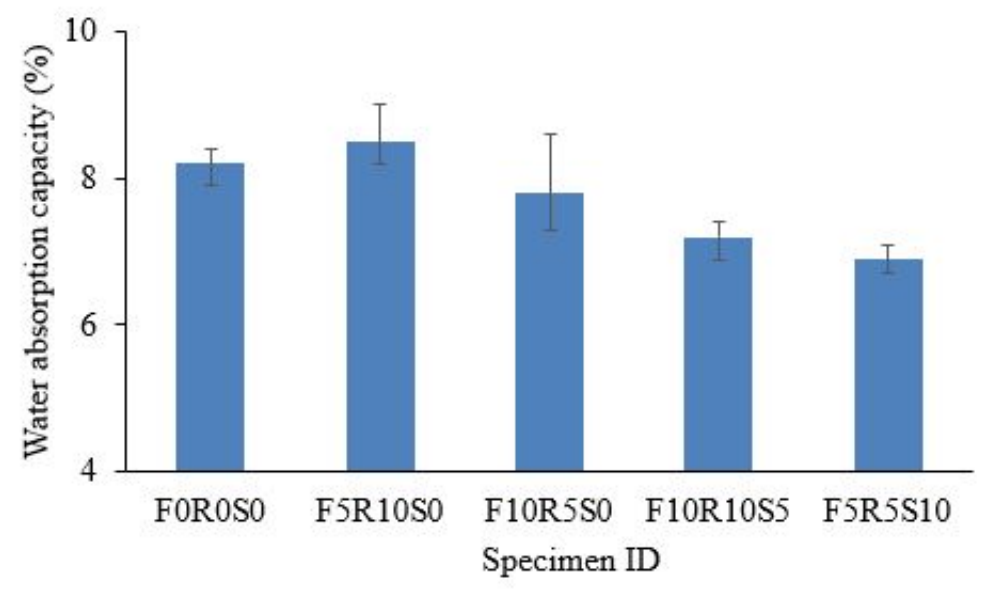

FiguRE 4. Water absorption capacity of different concrete specimens.

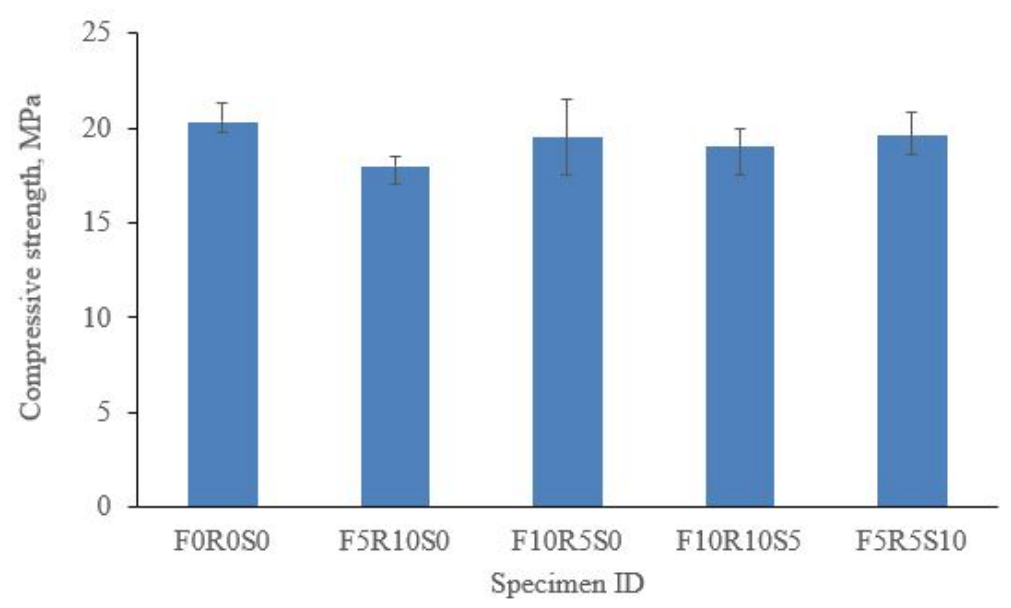

Figure 5. Compressive strength of different concrete specimens (28 days of age).

\subsection{MEChANICAL PERFORMANCE}

\subsubsection{COMPRESSIVE STRENGTH}

The compressive strength test results at 28 days of age of specimens (Fig. 5 show that the addition of any supplementary materials causes a reduction of strength. The addition of the FA and RHA as replacements of cement in concrete mixes gradually reduced the compressive strength as the level of replacement increased. The overall strength reduction observed for the test specimens was around 3.99\%-11.42\%, depending on the replacement ratio. This result is consistent with those in previous studies [2, 3, 7, 20]. The FA has a better binding properties than the RHA, therefore a lower strength reduction was observed for the FA than for the RHA. Specifically, F5R10S0 specimens show around $7.74 \%$ lower compressive strength than F10R5S0 specimens. In the present study, the lower fineness of the FA and RHA can be the cause of the strength reduction. The rapid pozzolanic action and accelerated hydration is related to the addition of fine FA and RHA; therefore, an addition of very fine FA and RHA is required to enhance the strength [25]. Additionally, the RHA produced from uncontrolled burning has a high carbon content and shows a low reactivity because of the crystalline particle structure [33].

The replacement of natural sands by the SD caused an improvement in the strength of concrete. This finding agrees well with those in current studies [8, 43, 57]. The lost strength of the FA and RHA added concrete compared to the control have been recovered, to some extent, after the addition of the SD in the mix. The F5R5S10 specimen shows moderate strength compared to the ordinary concrete with a strength lower only by $3.5 \%$. The fracture surfaces of different specimens showed that the most densely packed specimens were those of F5R5S10, which also showed a lower water absorption after hardening as a proof of a densely packed matrix. But the concrete, which contains a large amount of RHA, showed porous structures at the hardened state. This happened due to the low binding energy and inferior cementitious activity of the untreated coarser RHA, which may contain impurities and prevent the hydration and formation of the C-S-H link [55]. Meanwhile, the addition of the SD provides stiffnes to the ITZ, which creates a strong surface for the load transfer and stress distribution [56. Hence, 


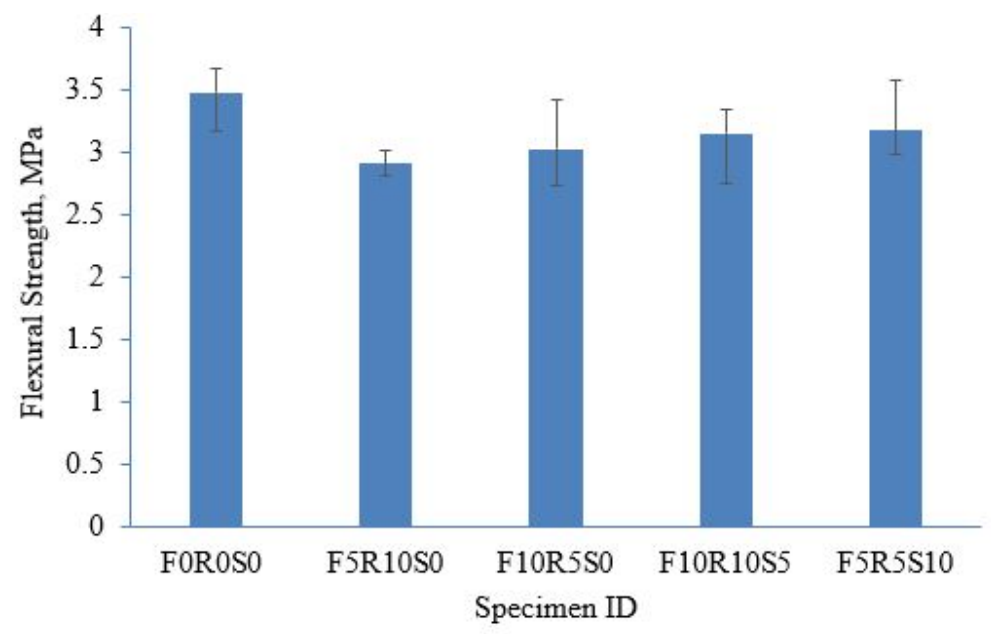

FiguRE 6. Flexural strength of different concrete specimens (28 days of age).

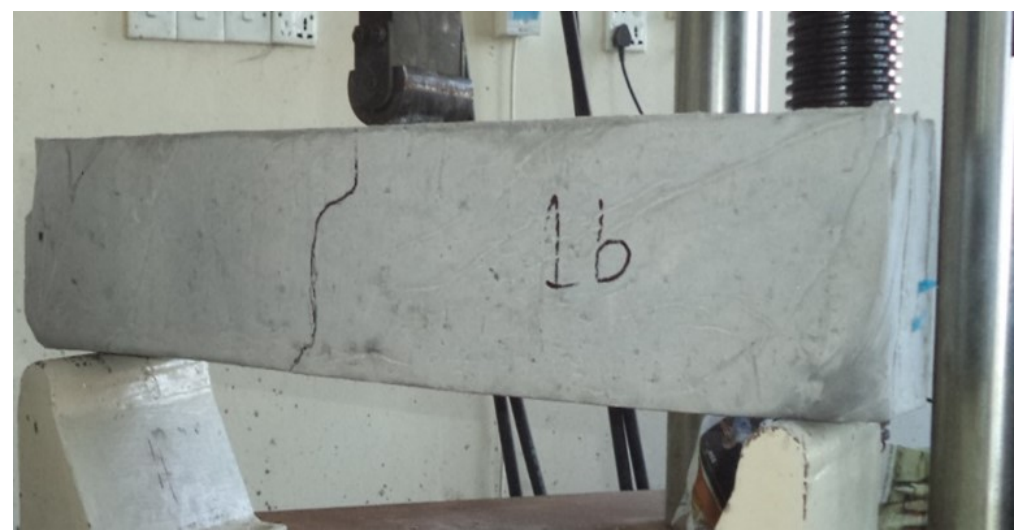

FIgURE 7. Failure mode of sustainable green concrete specimen under bending.

a lower amount of the RHA and a higher amount of the SD can be beneficial for the strength development. For this reason, the lowest strength was observed for F5R10S0 and highest was for F5R5S10. Therefore, a $10 \% \mathrm{wt}$ replacement of cement by equal parts of the FA and RHA and a $10 \%$ wt replacement of natural sands by the SD is the optimum for this experiment in terms of compressive strength.

\subsubsection{Flexural STRENGTh}

The overall flexural strength of specimens with different percentages of the FA and RHA is between 2.91 and $3.18 \mathrm{MPa}$ at 28 days of age, which is around $8.62 \%-16.4 \%$ lower than that of control specimens (Fig. 6). The FA and RHA contains considerably lower $\mathrm{CaO}$ than the OPC, thereby causing a low energy in bonding within the concrete 3, , 7, 20. Thus, the sustainable concrete specimens show a lower flexural strength than the control specimens. However, the sustainable concrete specimens show a reliable mechanical strength due to the high pozzolanicity in the FA- and RHA-based concretes caused by their very high specific surface area and the accelerated reaction between calcium hydroxide and silica 3,55 . Meanwhile, the addition of the SD to concrete is very effective in terms of the strength improvement. The
SD can transfer load to a wider range of its adjacent coarse aggregates than natural sands, and this helps improve the flexural strength of concrete. High fineness of these supplementary materials can help to enhance the overall performance of composites because fine materials showed an improved packing density. The graded SD is effective because it provides a less porous structure after hardening. Consequently, the density along the interfacial transition zone and mechanical strength are improved. All the specimens fail in the brittleness test by a single crack along the mid span, which is very near the loading point (Fig. 7). This happened because of the addition of the RHA generally increases the brittleness of concrete [59].

\subsubsection{Splitting tensile Strength}

Fig. 8 illustrates the variation in splitting tensile strength of the different concrete specimens at 28 days of age. The splitting tensile strength of concrete specimens is the load carrying capacity in the transverse direction and is applied perpendicularly to the horizontal axis. Therefore, it is related to the compressive strength. The splitting tensile strength of sustainable concrete specimens was around $7.52 \%-14.16 \%$ lower than that of the control concrete. The reduction in strength considerably depends on the percentage re- 


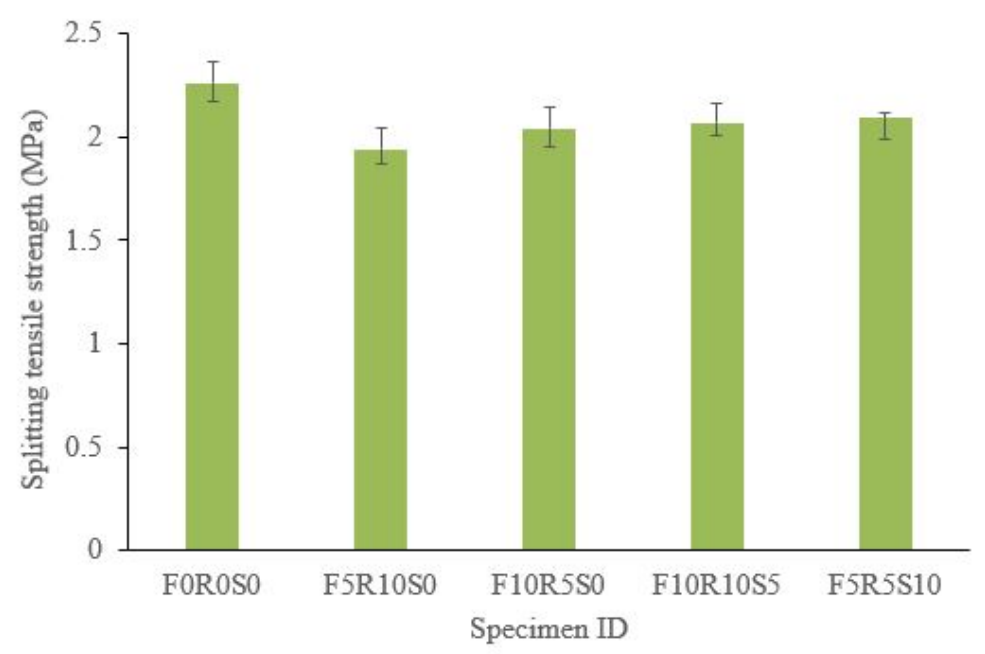

FiguRE 8. Splitting tensile strength of different concrete specimens (28 days of age).

placement level and mixing accuracy of the concrete mix. Poor mixing and compaction lead to porous structures, which lead to the reduction in strength. Due to its sharp and angular shape, the SD provides interlocking within the concrete matrix, and therefore resist greater loads than a natural sand-based concrete. Meanwhile, the stiffness provided by the SD against tensile stress was found higher compared to natural sands due to the interlocking of the binding agent by the rough surface of the SD 56 . The addition of the SD of up to $10 \%$ wt as a replacement of natural sands reliably improves the mechanical properties and can be used in an amount up to $15 \% \mathrm{wt}$, as found in [40. A further addition of the SD causes a very brittle concrete matrix, which is not expected.

\section{Performance of Reinforced SPECIMENS}

Bending test of steel reinforced concrete (RC) specimens was performed to evaluate the applicability and performance of the sustainable green concrete in steel reinforced concrete. The specimens were prepared by reinforcing beam specimens of $150 \mathrm{~mm} \times 150 \mathrm{~mm} \times$ $700 \mathrm{~mm}$ with four $12 \mathrm{~mm}$-diameter mild steel deformed bars; two of which were placed along soffit, and the other two were placed at the top. The stirrups were $8 \mathrm{~mm}$-diameter deformed bars placed at a distance of $150 \mathrm{~mm}$ centre to centre. The yield strength and ultimate strength of the $12 \mathrm{~mm}$ steel reinforcement was $423 \mathrm{MPa}$ and $619 \mathrm{MPa}$, respectively, and $414 \mathrm{MPa}$ and $625 \mathrm{MPa}$, respectively, for the $8 \mathrm{~mm}$ diameter bars. The beams were cast with a concrete cover maintained around $25 \mathrm{~mm}$.

Fig. 9 shows the flexural strength of these reinforced concrete beams cast with different mixtures. The additions of the FA and SD show a significantly improved flexural strength of these specimens, but the addition of the RHA reduces the strength of the control specimens. The F10R5S0 and F5R5S10 specimens have a $20 \%$ and $26 \%$ improvement in strength, respectively, compared with the control specimens. However, the addition of the RHA of more than $5 \%$ wt considerably reduces the flexural strength. All of the RC beams failed due to crushing of concrete and the failure was initiated by shear cracks (Fig. 10). Meanwhile, the control specimen with ordinary sand and OPC fails in flexure with flexural cracks induced in mid span under the maximum bending zone. The reason is that the shear strength of the concrete is low in these sustainable concrete specimens, which causes a failure in materials before considerable yielding of the steel reinforcements. The analysis of the failure mode and strength diagram shows that the use of the SD strengthens the tension and compression capacity of the concrete due to its filler and stress-transferring effects. However, the use of the RHA in excess amounts has the opposite effect. All the supplementary materials negatively affect the properties of concrete when they exceed the optimum level. The experiment shows that the sustainable concrete mixes are applicable in moderate amounts for an under-reinforced structural system to produce lightweight and low-cost structural systems. Generally, the lowest grade of concrete required for the RC member construction for typical and dynamic loading conditions is $\mathrm{C} 12 / \mathrm{C} 15$ concrete [39]. In this research, the developed sustainable green concrete can be classified as grade $\mathrm{C} 15$ and $\mathrm{C} 20$ concrete, and could be an equivalent to a normal grade M20 and M25 concrete, therefore, being suitable for RC construction according to IS 456-2000 60] and AS 3600-2009 61].

\section{Correlation Between hardened PROPERTIES}

The analysis of the mechanical properties and fracture surface (Fig. 11) of all types of concrete specimens reveals a general relationship of split tensile and flexural strengths of the concrete with the compressive strength. The minimum bonding between materials in specimens is found for $10 \%$ wt of the RHA. The 


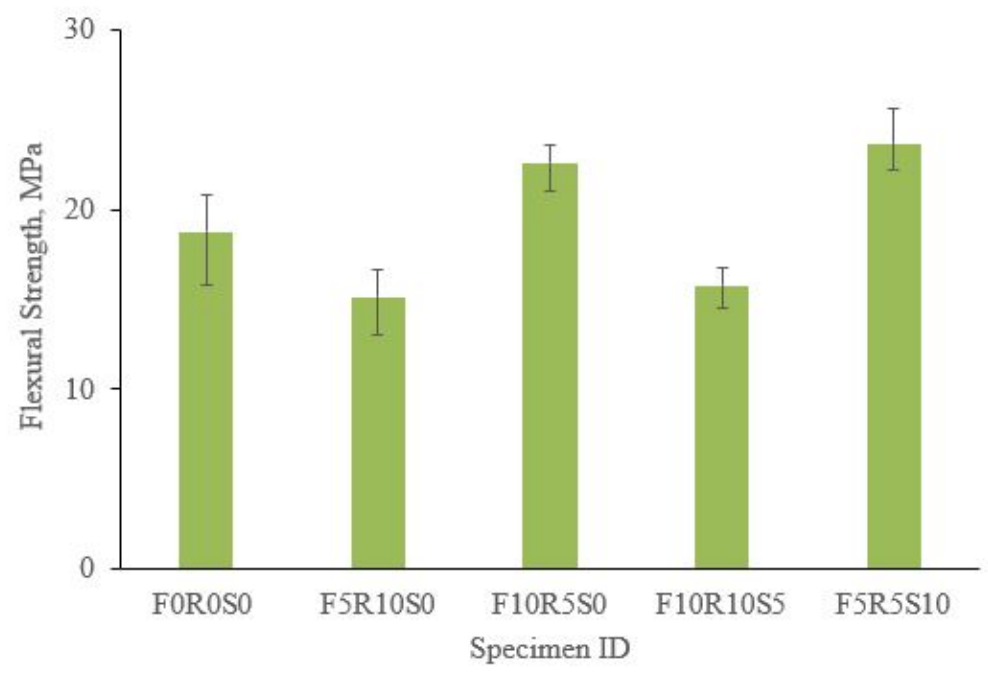

Figure 9. Flexural strength of RC beam with different concrete mixes.

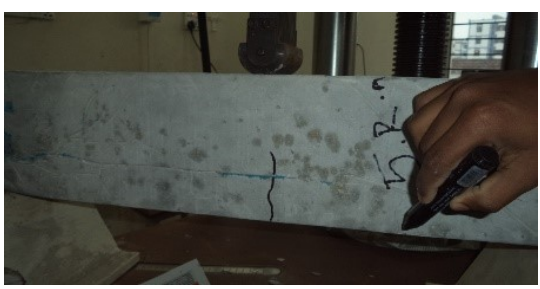

(A) . F0R0S0.

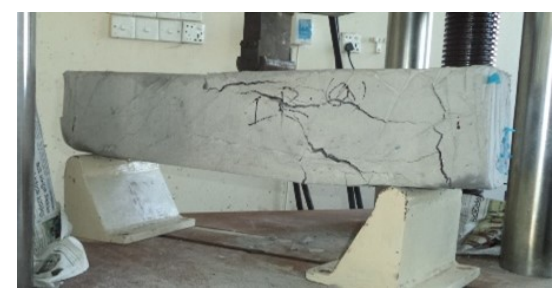

(в) . F5R10S0.

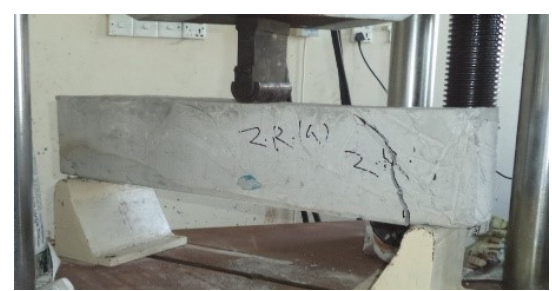

(c) . F10R5S0.

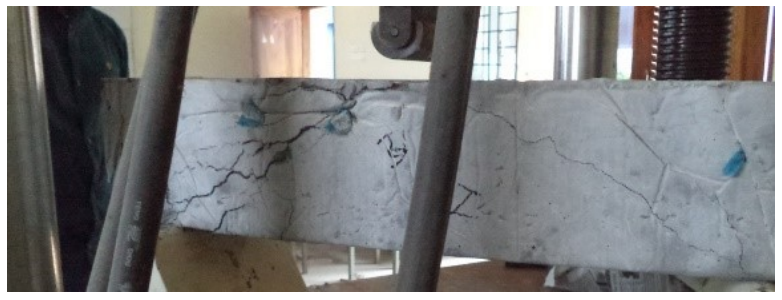

(D) . F10R10S5.

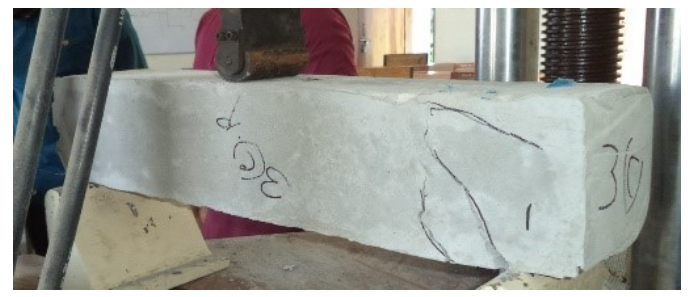

(E) . F5R5S10.

FIGURE 10. Failure mode of RC beam specimens cast with different concrete mixes.

observation of less loose materials and lower porosity along the interface of stone aggregates and other materials provides a high bond development in concrete (Fig. $11 \mathrm{~b}$ and $11 \mathrm{~d}$ ). With a high amount of the RHA, the interface of the stone aggregate and binder paste is weakened because of the lesser reactivity of the RHA. The poor bond formation within the concrete matrix causes a decrease in the compressive strength compared with the other specimens with a low RHA content. The high-water absorption result is the proof of the porous structure of these specimens, thus, these specimens possess low splitting tensile strength and flexural strength. However, the combined addition of the FA and RHA accelerates the development of strength in early stages. The F10R5S0 specimens show around $8.4 \%$ higher compressive strength than the F5R10S0 specimens. Similarly, the variations in flexural and splitting tensile strength are consistent with this result. Therefore, the FA exhibits a higher cementitious activity than the RHA. The addition of the SD causes filler and crack-bridging effects within the sustainable concrete, which can then absorb a large amount of energy under compression. This condition caused a strength increment for the RHA- and FA-based concretes after the addition of the SD. The analysis of the fracture surface and the water absorption test results indicates that the SDbased concrete shows a dense matrix. All the specimens show a general trend of variation of strength, and most of the results are consistent with those of the compressive test. This study finds a $11.42 \%$, $3.99 \%, 6.50 \%$, and $3.49 \%$ reduction in compressive strength; a $16.4 \%, 12.93 \%, 9.48 \%$, and $8.62 \%$ reduction in flexural strength; and a $14.16 \%, 9.74 \%, 8.41 \%$, and $7.52 \%$ reduction in splitting tensile strength for F5R10S0, F10R5S0, F10R10S5, and F5R5S10 specimens, respectively, compared with the control F0R0S0 specimen. As the compressive strength varied with the addition of any by-product, the splitting tensile strength and flexural strength showed a nearly similar trend in variation for the same concrete. Therefore, a very general conclusion on mechanical properties can 


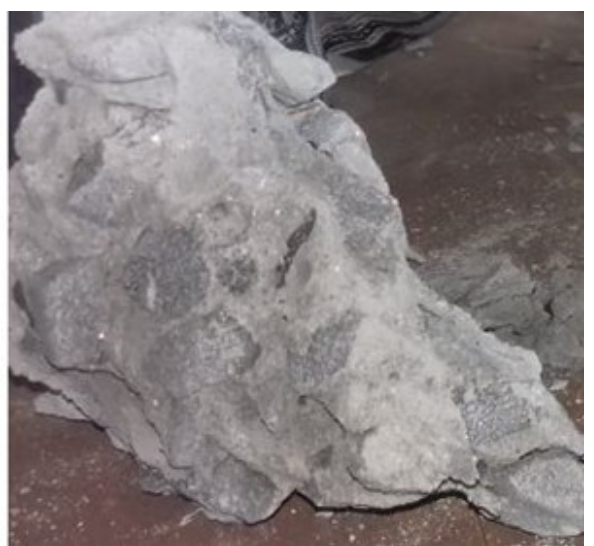

(A) . F5R10S0.

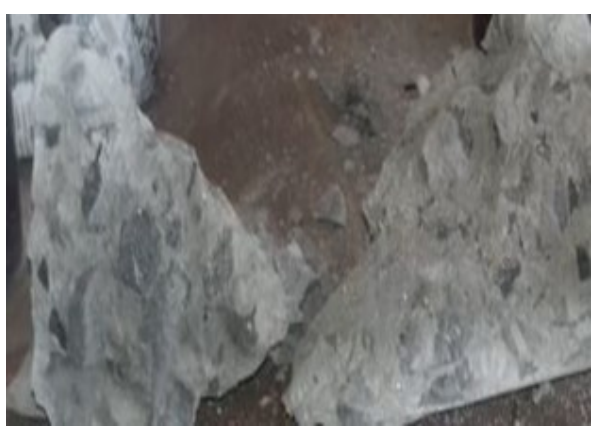

(c) . F10R10S5.

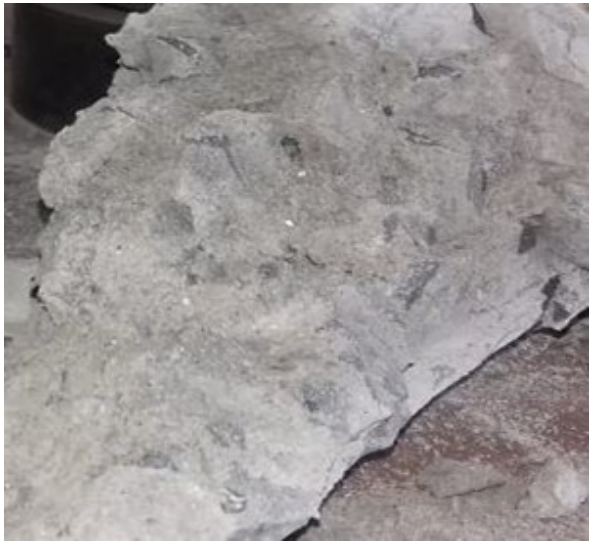

(в) . F10R5S0.

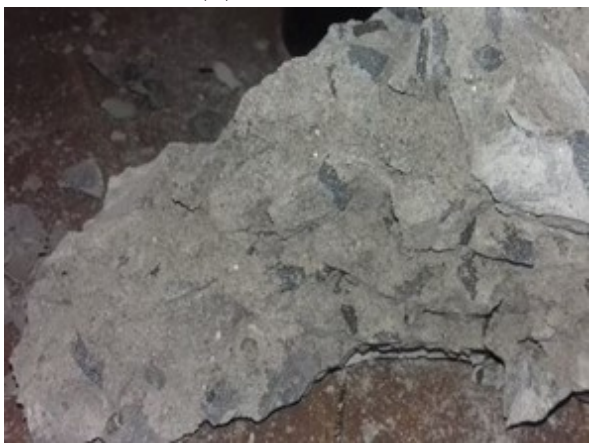

(D) . F5R5S10.

FigURE 11. Fracture surfaces of different hardened concrete mixtures.

be obtained with the addition of these by-products in concrete.

\subsection{COMPARISON OF RESUlts}

The experimental results show that the optimum value of replacement of cement is with $5 \%$ wt of the FA and $5 \%$ wt of the RHA with $10 \%$ wt of the SD as a replacement of sand. The addition of the FA can be increased up to $10 \% \mathrm{wt}$, because this amount improves strength. However, a further addition of any of the three materials may increase the porosity and strength because of the corresponding reduction in bonding energy and an occurrence of agglomeration. This result agrees well with those of current studies. Chindaprasirt et al. [22] indicated that additions of $10 \% \mathrm{wt}$ of the FA and $10 \%$ wt of the RHA in concrete reduce the early strength of concrete and slightly increase the strength during the aging process. However, further addition considerably decreases the compressive strength [22, 25]. Jung et al. [30] added limestone powder with a high content of calcium oxide to increase the strength of the FA- and RHA-based concretes. They found approximate $8.2 \%$ and $14.75 \%$ increases in compressive strength when $5 \%$ wt and $10 \%$ wt of a limestone powder is added to specimens with $5 \% \mathrm{wt}$ and $10 \%$ wt of RHA and FA, respectively. The addition of the RHA by more than $10 \%$ wt reduces the strength, and this result is also consistent with the one obtained by Kathirvel et al. 62. The addition of hydrated lime can accelerate the pozzolanic reaction in the RHA-concrete 63. Additionally, nano-silica can also help to improve the strength of the RHAconcrete 59. Moreover, any pre-treatment of the RHA and FA can improve the strength properties, because fine particles produce a dense matrix [3, 64]. The sustainable concrete containing the FA, RHA, and SD simultaneously has rarely been investigated. The current experiment shows that the addition of the SD of up to $10 \%$ wt as a replacement of natural sands improves the performance. This performance is consistent with the previous result without considering the cement replacement level [8, 57]. However, a further addition of the SD may cause agglomeration and porous structure, which weaken the concrete. Therefore, the optimum level of replacement of natural sands by the SD is $10 \%$ wt.

\section{Conclusion}

The performance of a sustainable green concrete with a partial replacement of cement and sand by incorporating the FA, RHA, and SD in different percentages was investigated. However, the production of a sustainable and low-cost concrete with the studied by-products (i.e., FA, RHA, and SD) as partial replacements of cement and sand is still challenging. The addition of FA, RHA, and SD in concrete showed insignificant decreases in strength, up to a certain limit. From the experimental test results, the following conclusions can be drawn: 
- The binding action of the FA is considerably superior to that of the RHA, but both show similar results when no treatment is applied to the concrete mix.

- The use of the SD as a replacement of natural sands in concrete is considerably effective and improves the mechanical properties, thereby reducing the capacity of water absorption by enhancing the density of the matrix.

- The reduction in the water absorption capacity of the FA-, RHA-, and SD-based concrete is a sign of improvement in durability.

- Around $20 \%$ of ordinary materials in concrete can be replaced by the studied by-products or waste materials (i.e., FA, RHA, and SD) without significantly compromising the strength properties. However, an excess amount may exhibit negative effects. The optimum combination found in this study is $5 \% \mathrm{wt}$ of the FA and $5 \%$ wt of the RHA as replacements of cement and $10 \%$ wt of the SD as a replacement of natural sands without decreasing the strength of concrete.

- The replacement of cement by the FA and RHA provides sustainability in the construction industry and waste management systems, and the replacement of natural sands by the SD can help saving natural resources.

Several studies have been conducted on the individual uses of the FA, RHA, and SD in concrete. However, the combined effect of these materials in concrete is still under investigation. Extensive chemical analyses and microstructural studies are required to establish the appropriateness of these materials in terms of strength and durability against high loads and exposure conditions.

\section{ACKNOWLEDGEMENTS}

The experimental work was carried out at Pabna University of Science and Technology, Pabna-6600, Bangladesh. The authors are grateful to the Chairman and the Faculty Members of the Department of Civil Engineering for the facilities provided and co-operation rendered. The authors gratefully acknowledge the support provided by the Department of Civil Engineering, College of Engineering, Prince Sattam Bin Abdulaziz University, Saudi Arabia.

\section{REFERENCES}

[1] I. Taji, S. Ghorbani, J. De Brito, et al. Application of statistical analysis to evaluate the corrosion resistance of steel rebars embedded in concrete with marble and granite waste dust. Journal of Cleaner Production 210:837 - 846, 2019. DOI:10.1016/j.jclepro.2018.11.091

[2] J. Alex, J. Dhanalakshmi, B. Ambedkar.

Experimental investigation on rice husk ash as cement replacement on concrete production. Construction and Building Materials 127:353 - 362, 2016.

DOI:10.1016/j.conbuildmat.2016.09.150.
[3] A. K. Saha. Effect of class F fly ash on the durability properties of concrete. Sustainable environment research 28(1):25 - 31, 2018. DOI:10.1016/j.serj.2017.09.001

[4] A. Siddika, M. A. Al Mamun, R. Alyousef, H. Mohammadhosseini. State-of-the-art-review on rice husk ash: A supplementary cementitious material in concrete. Journal of King Saud University - Engineering Sciences 2020. DOI:10.1016/j.serj.2017.09.001.

[5] B. Bahoria, D. Parbat, P. Nagarnaik. XRD analysis of natural sand, quarry dust, waste plastic (ldpe) to be used as a fine aggregate in concrete. Materials Today: Proceedings 5(1):1432 - 1438, 2018.

DOI:10.1016/j.matpr.2017.11.230.

[6] M. R. Hasan, A. Siddika, M. P. A. Akanda, M. R. Islam. Effects of waste glass addition on the physical and mechanical properties of brick. Innovative Infrastructure Solutions 6(36):1 - 13, 2021. DOI:10.1007/s41062-020-00401-z.

[7] A. Siddika, M. A. Al Mamun, M. H. Ali. Study on concrete with rice husk ash. Innovative Infrastructure Solutions 3(18):1 - 9, 2018. DOI:10.1007/s41062-018-0127-6

[8] S. Ghorbani, I. Taji, M. Tavakkolizadeh, et al. Improving corrosion resistance of steel rebars in concrete with marble and granite waste dust as partial cement replacement. Construction and Building Materials 185:110 - 119, 2018. DOI:10.1016/j.conbuildmat.2018.07.066

[9] A. Siddika, M. A. Al Mamun, R. Alyousef, et al. Properties and utilizations of waste tire rubber in concrete: A review. Construction and Building Materials 224:711 - 731, 2019. DOI:10.1016/j.conbuildmat.2019.07.108

[10] A. Hajimohammadi, T. Ngo, A. Kashani. Glass waste versus sand as aggregates: The characteristics of the evolving geopolymer binders. Journal of Cleaner Production 193:593 - 603, 2018. DOI:10.1016/j.jclepro.2018.05.086

[11] H. Mohammadhosseini, M. M. Tahir. Production of sustainable green concrete composites comprising industrial waste carpet fibres. In Green Composites, pp. 25-52. Springer, 2019.

[12] R. Alyousef, H. Alabduljabbar,

H. Mohammadhosseini, et al. Utilization of sheep wool as potential fibrous materials in the production of concrete composites. Journal of Building Engineering 30:101216, 2020. DOI:10.1016/j.jobe.2020.101216.

[13] R. Alyousef, K. Aldossari, O. Ibrahim, et al. Effect of sheep wool fiber on fresh and hardened properties of fiber reinforced concrete. International Journal of Civil Engineering and Technology 10:190 - 199, 2019.

[14] Y. Mugahed Amran, R. Alyousef, H. Alabduljabbar, et al. Performance properties of structural fibred-foamed concrete. Results in Engineering 5:100092, 2020. DOI:10.1016/j.rineng.2019.100092.

[15] H. Assaedi, T. Alomayri, A. Siddika, et al. Effect of nanosilica on mechanical properties and microstructure of PVA fiber-reinforced geopolymer composite (PVA-FRGC). Materials 12(21):3624, 2019. DOI:10.3390/ma12213624. 
[16] A. Siddika, M. A. Al Mamun, W. Ferdous, et al. 3D-printed concrete: applications, performance, and challenges. Journal of Sustainable Cement-Based Materials 9(3): 127 - 164, 2020. DOI:10.1080/21650373.2019.1705199

[17] R. Prakash, R. Thenmozhi, S. N. Raman, et al. Mechanical characterisation of sustainable fibre-reinforced lightweight concrete incorporating waste coconut shell as coarse aggregate and sisal fibre. International Journal of Environmental Science and Technology pp. $1-12,2020$. DOI:10.1007/s13762-020-02900-z.

[18] A. K. Saha, P. K. Sarker, V. Golovanevskiy. Thermal properties and residual strength after high temperature exposure of cement mortar using ferronickel slag aggregate. Construction and Building Materials 199:601 - 612, 2019. DOI:10.1016/j.conbuildmat.2018.12.068

[19] R. Prakash, R. Thenmozhi, S. N. Raman, C. Subramanian. Characterization of eco-friendly steel fiber-reinforced concrete containing waste coconut shell as coarse aggregates and fly ash as partial cement replacement. Structural Concrete 21:437 - 447, 2019. DOI:10.1002/suco.201800355

[20] F. Moghaddam, V. Sirivivatnanon, K. Vessalas. The effect of fly ash fineness on heat of hydration, microstructure, flow and compressive strength of blended cement pastes. Case Studies in Construction Materials 10:e00218, 2019. DOI:10.1016/j.cscm.2019.e00218

[21] P. Chindaprasirt, C. Jaturapitakkul, T. Sinsiri. Effect of fly ash fineness on compressive strength and pore size of blended cement paste. Cement and Concrete Composites 27(4):425 - 428, 2005. DOI:10.1016/j.cemconcomp.2004.07.003

[22] P. Chindaprasirt, S. Rukzon, V. Sirivivatnanon. Resistance to chloride penetration of blended portland cement mortar containing palm oil fuel ash, rice husk ash and fly ash. Construction and Building Materials 22(5):932 - 938, 2008. DOI:10.1016/j.conbuildmat.2006.12.001.

[23] G. L. Golewski, T. Sadowski. A study of mode III fracture toughness in young and mature concrete with fly ash additive. In Advanced Materials and Structures VI, vol. 254 of Solid State Phenomena, pp. 120 - 125 . 2016. DOI:10.4028/www.scientific.net/SSP.254.120.

[24] R. Prakash, R. Thenmozhi, S. N. Raman, et al. An investigation of key mechanical and durability properties of coconut shell concrete with partial replacement of fly ash. Structural Concrete pp. $1-12$. DOI:10.1002/suco.201900162

[25] V. N. Kanthe, S. V. Deo, M. Murmu. Effect of fly ash and rice husk ash on strength and durability of binary and ternary blend cement mortar. Asian Journal of Civil Engineering 19:963 - 970, 2018. DOI:10.1007/s42107-018-0076-6.

[26] M. A. Mamun, M. S. Islam. Experimental investigation of chloride ion penetration and reinforcement corrosion in reinforced concrete member. Journal of Construction Engineering and Project Management 7:26 - 29, 2017. DOI:10.6106/JCEPM.2017.3.30.026
[27] G. L. Golewski. Estimation of the optimum content of fly ash in concrete composite based on the analysis of fracture toughness tests using various measuring systems. Construction and Building Materials 213:142 155, 2019. DOI:10.1016/j.conbuildmat.2019.04.071.

[28] S. Pavía, R. Walker, P. Veale, A. Wood. Impact of the properties and reactivity of rice husk ash on lime mortar properties. Journal of Materials in Civil Engineering 26(9):04014066, 2014. DOI:10.1061/(ASCE)MT.1943-5533.0000967.

[29] S. N. Raman, T. Ngo, P. Mendis, H. B. Mahmud. High-strength rice husk ash concrete incorporating quarry dust as a partial substitute for sand. Construction and Building Materials 25(7):3123 - 3130, 2011. DOI:10.1016/j.conbuildmat.2010.12.026

[30] S.-H. Jung, S. Velu, K. Subbiah, et al. Microstructure characteristics of fly ash concrete with rice husk ash and lime stone powder 12(17):1 - 9, 2018.

[31] C. Fapohunda, B. Akinbile, A. Shittu. Structure and properties of mortar and concrete with rice husk ash as partial replacement of ordinary portland cement. International Journal of Sustainable Built Environment 6(2):675 - 692, 2017. DOI:10.1016/j.ijsbe.2017.07.004.

[32] C. L. Hwang, S. Chandra. 4 - the use of rice husk ash in concrete. In Waste Materials Used in Concrete Manufacturing, pp. 184 - 234. William Andrew Publishing. DOI:10.1016/b978-081551393-3.50007-7

[33] D. G. Nair, K. S. Jagadish, A. Fraaij. Reactive pozzolanas from rice husk ash: An alternative to cement for rural housing. Cement and Concrete Research 36(6):1062 - 1071, 2006. DOI:10.1016/j.cemconres.2006.03.012

[34] K. C. Panda, S. D. Prusty. Influence of silpozz and rice husk ash on enhancement of concrete strength. Advances in concrete construction 3(3):203 - 221, 2015. DOI:10.12989/acc.2015.3.3.203

[35] G. Cordeiro, R. Toledo Filho, E. Fairbairn. Use of ultrafine rice husk ash with high-carbon content as pozzolan in high performance concrete. Materials and Structures 42(7):983 - 992, 2008. DOI:10.1617/s11527-008-9437-z

[36] C. Elakkiah. Rice Husk Ash (RHA) - The Future of Concrete. In Lecture Notes in Civil Engineering. Springer, Singapore, 2019. DOI:10.1007/978-981-13-3317-0_39

[37] A. Abalaka. Strength and some durability properties of concrete containing rice husk ash produced in a charcoal incinerator at low specific surface. International Journal of Concrete Structures and Materials 7(4):287 293, 2013. DOI:10.1007/s40069-013-0058-8.

[38] G. L. Golewski. Energy savings associated with the use of fly ash and nanoadditives in the cement composition. Energies 13(9):2184, 2020.

[39] G. Golewski. A novel specific requirements for materials used in reinforced concrete composites subjected to dynamic loads. Composite Structures 223:110939, 2019. DOI:10.1016/j.compstruct.2019.110939 
[40] S. Singh, R. Nagar, V. Agrawal. A review on properties of sustainable concrete using granite dust as replacement for river sand. Journal of Cleaner Production 126:74 - 87, 2016. DOI:10.1016/j.jclepro.2016.03.114

[41] B. K. Meisuh, C. K. Kankam, T. K. Buabin. Effect of quarry rock dust on the flexural strength of concrete. Case Studies in Construction Materials 8:16 - 22, 2018. DOI:10.1016/j.cscm.2017.12.002

[42] M.-C. Han, D. Han, J.-K. Shin. Use of bottom ash and stone dust to make lightweight aggregate.

Construction and Building Materials 99:192 - 199, 2015. DOI:10.1016/j.conbuildmat.2015.09.036

[43] H. Li, F. Huang, G. Cheng, et al. Effect of granite dust on mechanical and some durability properties of manufactured sand concrete. Construction and Building Materials 109:41 - 46, 2016. DOI:10.1016/j.conbuildmat.2016.01.034.

[44] S. Mundra, P. Sindhi, V. Chandwani, et al. Crushed rock sand - An economical and ecological alternative to natural sand to optimize concrete mix. Perspectives in Science 8:345 - 347, 2016. Recent Trends in Engineering and Material Sciences, DOI:10.1016/j.pisc.2016.04.070

[45] ASTM C618-03 - Standard specification for coal fly ash and raw or calcined natural pozzolan for use in concrete. Standard, American Society for Testing and Materials, West Conshohocken, 2003. DOI:10.1520/C0618-03.

[46] B. Hellack. Specific surface area by Brunauer-EmmettTeller (BET) theory. Tech. rep. www nanopartikel. info/wp-content/uploads/2020/11/nanOxiMet_SOP_ Specific-surface-area-analysis-by-BET-theory_ V1.pdf

[47] ASTM C33-03 - Standard specification for concrete aggregates. Standard, American Society for Testing and Materials, West Conshohocken, 2003. DOI:10.1520/C0033-03.

[48] ASTM C143/C143-03 - Standard test method for slump of hydraulic-cement concrete. Standard, American Society for Testing and Materials, West Conshohocken, 2003. DOI:10.1520/C0143_C0143M-03

[49] ASTM C642-06 - Standard test method for density, absorption, and voids in hardened concrete. Standard, American Society for Testing and Materials, West Conshohocken, 2006. DOI:10.1520/C0642-06

[50] ASTM C39/C39M-18 - Standard test method for compressive strength of cylindrical concrete specimens. Standard, American Society for Testing and Materials, West Conshohocken, 2018. DOI:10.1520/C0039_C0039M-18

[51] ASTM C78/C78M-18 - Standard test method for flexural strength of concrete (using simple beam with third-point loading). Standard, American Society for Testing and Materials, West Conshohocken, 2018. DOI:10.1520/C0039_C0039M-18

[52] ASTM C 496/C496M-11 - Standard test method for splitting tensile strength of cylindrical concrete specimens. Standard, American Society for Testing and Materials, West Conshohocken, 2011.

DOI:10.1520/C0496_C0496M-11
[53] Z. Yao, X. Ji, P. Sarker, et al. A comprehensive review on the applications of coal fly ash. Earth-Science Reviews 141:105 - 121, 2015. DOI:10.1016/j.earscirev.2014.11.016

[54] R. Prakash, R. Thenmozhi, S. N. Raman. Mechanical characterisation and flexural performance of eco-friendly concrete produced with fly ash as cement replacement and coconut shell coarse aggregate. International Journal of Environment and Sustainable Development 18(2):131 - 148, 2019. DOI:10.1504/IJESD.2019.099491

[55] S. K. Antiohos, J. G. Tapali, M. Zervaki, et al. Low embodied energy cement containing untreated RHA: A strength development and durability study.

Construction and Building Materials 49:455 - 463, 2013 DOI:10.1016/j.conbuildmat.2013.08.046.

[56] A. Rana, P. Kalla, H. K. Verma, J. K. Mohnot. Recycling of dimensional stone waste in concrete: A review. Journal of cleaner production 135:312 - 331, 2016. DOI:10.1016/j.jclepro.2016.06.126

[57] S. Ghorbani, I. Taji, J. De Brito, et al. Mechanical and durability behaviour of concrete with granite waste dust as partial cement replacement under adverse exposure conditions. Construction and Building Materials 194:143 - 152, 2019. DOI:10.1016/j.conbuildmat.2018.11.023.

[58] G. Sivakumar, R. Ravibaskar. Investigation on the hydration properties of the rice husk ash cement using FTIR and SEM. Applied Physics Research 1(2):71 - 77, 2009. DOI:10.5539/apr.v1n2p71

[59] B. S. Thomas. Green concrete partially comprised of rice husk ash as a supplementary cementitious material A comprehensive review. Renewable and Sustainable Energy Reviews 82:3913 - 3923, 2018. DOI:10.1016/J.RSER.2017.10.081.

[60] IS 456:2000. Concrete, Plain and Reinforced. Bur Indian Stand Dehli. Standard, 2000.

[61] Reinforced concrete design: in accordance with AS 3600-2009. Standard, Standards Australia, 2011.

[62] Strength, R. H. A. Durability Properties of Quaternary Cement Concrete Made with Fly Ash, L. Powder. P. kathirvel and v. saraswathy and s. p. karthik and a. s. s. sekar. Arabian Journal for Science and Engineering 38:589 - 598, 2013. DOI:10.1007/s13369-012-0331-1

[63] P. A. Adesina, F. A. Olutoge. Structural properties of sustainable concrete developed using rice husk ash and hydrated lime. Journal of Building Engineering 25:100804, 2019. DOI:10.1016/j.jobe.2019.100804

[64] R. Zerbino, G. Giaccio, G. C. Isaia. Concrete incorporating rice-husk ash without processing. Construction and building materials 25(1):371 - 378, 2011. DOI:10.1016/j.conbuildmat.2010.06.016 